\title{
The New Dimensions of Occupational Health
}

\author{
Michel P. Guillemin ${ }^{1,2}$ \\ ${ }^{1}$ University of Lausanne, Lausanne, Switzerland \\ ${ }^{2}$ Association Santé Globale \& Travail, Lausanne, Switzerland \\ Email: michel.guillemin@gmail.com
}

How to cite this paper: Guillemin, M.P. (2019) The New Dimensions of Occupational Health. Health, 11, 592-607. https://doi.org/10.4236/health.2019.115050

Received: April 24, 2019

Accepted: May 28, 2019

Published: May 31, 2019

Copyright $\odot 2019$ by author(s) and Scientific Research Publishing Inc. This work is licensed under the Creative Commons Attribution International License (CC BY 4.0).

http://creativecommons.org/licenses/by/4.0/

\begin{abstract}
Occupational Health $(\mathrm{OH})$ is an important chapter of Public Health but its visibility is poor and continues to decrease. Examples of this worrying trend show that it impacts on our society regarding health of the working population and the retired individuals and on the economy through huge expenses for health, absenteeism, psychosocial problems, loss of performance and quality of work, etc. To cope with this challenge and to give its right place to $\mathrm{OH}$, a global approach and a vision of this multidisciplinary field is needed as well as the development of emerging issues that stress, besides the prevention of occupational diseases, the promotion of "good health" through sciences like salutogenesis, positive psychology and the new findings of neuroscience. Moreover, all the partners involved in $\mathrm{OH}$ have to take their responsibility of this matter. The $\mathrm{OH}$ professionals have to enlarge the scope of their expertise; the academic institutions and research and education centers have to give more support to $\mathrm{OH}$ and the social partners and the decision-makers (politicians) have to put $\mathrm{OH}$ in their priorities. This paper is not a review of the new dimensions of $\mathrm{OH}$ but an overview of the emerging issues that have to be developed, based on the author's experience of more than 40 years.
\end{abstract}

\section{Keywords}

Work Changes, Emerging Issues, Global Concept, Worrying Trends, Responsibilities

\section{Introduction}

Occupational Health $(\mathrm{OH})$ is a very broad domain that includes a wide range of disciplines such as safety, hygiene, toxicology, medicine, nursing, psychiatry, psychology, ergonomics, sociology as well as a variety of related fields such as management, human resources, insurance, environment, legal provisions, etc. This may explain, in a way, why its visibility is rather poor in the society. More- 
over, it suffers-in the mind of a lot of people-from endemic prejudice and biased beliefs according to which it represents a brake on economy and businesses and is not quite relevant as a scientific area.

The aim of this paper is not to demonstrate why $\mathrm{OH}$ is an important chapter of Public Health $(\mathrm{PH})$ but to focus on the need to better understand the global concept of $\mathrm{OH}$ and the challenges it has to cope with.

Work is changing as well as aspirations of the new generations who look for values, such as fair trade, social justice, environmental protection, solidarity, etc. Therefore, $\mathrm{OH}$ has to answer these needs and to adapt its scope, competencies and objectives in order to be in line with this new vision.

In the first part, a few examples of negative developments regarding $\mathrm{OH}$ will be stressed to illustrate the real threats on this domain and to demonstrate the urgency to prevent any further expansion of this damaging trend.

In the second part, we will illustrate the present trends in approaching $\mathrm{OH}$ from a global perspective and the need to have a relevant basis defining what really $\mathrm{OH}$ is, in order to better understand the implications of these comprehensive approaches.

The third part will analyze the areas where $\mathrm{OH}$ is still behind the state of the art regarding health promotion and its different aspects. $\mathrm{OH}$ has to go faster than now, beyond the protection of workers' health and the prevention of diseases.

Finally, the responsibilities of the relevant actors who may modify the present situation and give more visibility to the considerable potentiality of $\mathrm{OH}$ for progressing towards a "healthier society" are shortly discussed.

The wide overlapping of $\mathrm{OH}$ and $\mathrm{PH}$ makes that the emerging issues presented in this article, as well as the role of $\mathrm{OH}$, are also concerning $\mathrm{PH}$. In other words, $\mathrm{OH}$ is an important chapter of $\mathrm{PH}$.

For every topic discussed in this paper, the amount of references that could be cited is huge. The selection has been made according to their scientific relevance and to their representative nature of the concerned topic.

\section{The Present Situation Reveals Worrying Trends}

\subsection{Continuous Increase of Psychosocial Problems}

Psychosocial problems, also designated as risks, have been known since more than 30 years ago and have been studied to better understand their impacts on health, their origins, their nature and the ways to prevent or to eradicate them. Thousands of papers have been published and our scientific knowledge can be considered as good. However, during this same period, they irrevocably increase, as illustrated in Figure 1, constructed from the periodic surveys of Eurofound (European Foundation for the Improvement of Living and Working Conditions), carried out every five years [1]. In 2015, two out of the three factors were not recorded anymore.

National surveys confirm this trend, for example in France [2] and in Switzerland [3]. 


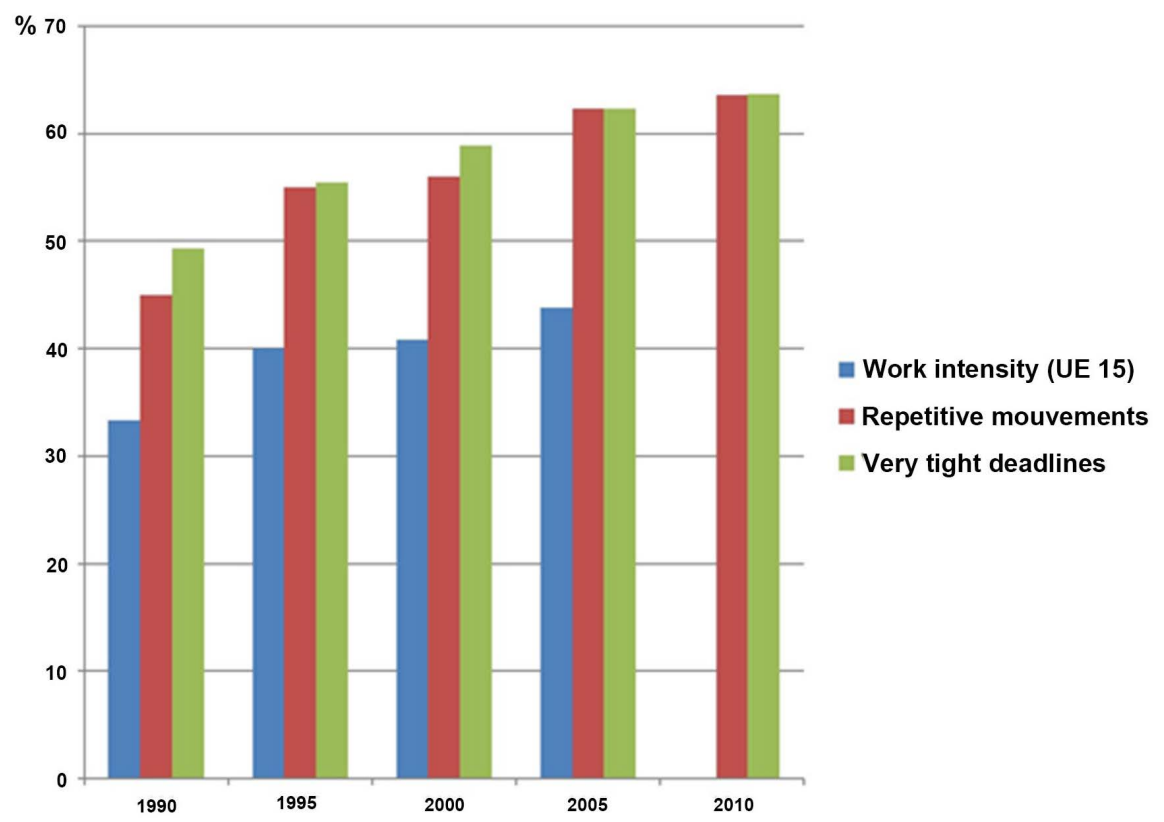

Figure 1. Graph showing the evolution of the percentage of workplaces concerned by three relevant stress factors (Work intensity; Repetitive movements; Very tight deadlines) in the periodic surveys of the European Foundation for the Improvement of Living and Working Conditions. In 2010, the work intensity factor was not anymore recorded.

These problems are linked with absenteeism, turnover, depression, suicides and loss of quality and performance of the enterprises as well as a negative impact on their image. All the effects represent a huge economic burden on the society.

Methods and strategies to manage these risks are known, and many review studies on the effectiveness of preventive strategies have been published showing that in some cases they are successful but of limited impact at a more global level [4]. So what are the reasons for that irrepressible epidemy? It is difficult to answer this question but there are two hypotheses: 1) A lack of awareness of managers and decision makers due to the poor visibility of $\mathrm{OH}$ as mentioned above and 2) A denial of the reality and a firm belief that short-term profit is the only and ultimate goal of the business.

\subsection{Continuous Increase of Social Inequalities}

In a similar way, the social inequalities instead of decreasing with the improvement of the life conditions and the good economic situation of many developed countries, continue to increase [5]. The gap between the top and bottom earners is still growing as well as the life expectancy between high and low social classes [6]. This means that the low social classes where usually the working conditions are worse than for the upper classes do not see any improvement in the quality of their lives. It has been shown, in Europe, that lower educated workers had higher risks of leaving paid employment than those with higher education. The disadvantaged position of lower educated persons on the labor market was primarily a result of a higher prevalence of poor health [7]. The European Agency 
for Occupational Safety and Health (OSHA) in its report "Adding inequality to injury, the costs of failing to protect workers on the job" [8] stated: The failure of many employers to prevent millions of work injuries and illnesses each year, and the failure of the broken workers compensation system to ensure that workers do not bear the costs of their injuries and illnesses are truly adding inequality to injury.

This problem of health inequalities at work is closely linked to the larger perspective of Public Health [9].

\subsection{Aggressive Political Decisions against OH (Biased Perception)}

Between the seventies and the end of the nineties, the development of $\mathrm{OH}$ was satisfactory and research and education as well as professional societies were well supported by all the social partners. The first signs of decline appeared in 2004, when the Federal Institute of Technology in Switzerland, decided to close its Institute of Hygiene and Applied Physiology well-known in ergonomics and in physiology of vision at the workplace, arguing that these fields of research were obsolete. Although the entire Swiss community of $\mathrm{OH}$ disciplines sent a protest letter to the government, the decision did not change.

In 2007, the new government of Sweden decided to close its National Institute for Working Life, one of the best references for $\mathrm{OH}$ in Europe. This political decision sent a shockwave to the international $\mathrm{OH}$ research community [10] and was taken before the international evaluation of the Institute, by a group of international experts, initiated by the previous government, was published [11].

In the following years, this trend was confirmed in other countries where the financial backing for $\mathrm{OH}$ research and education was significantly reduced. Moreover, the visibility of $\mathrm{OH}$ was also damaged by the inclusion of dedicated structures into larger organizations. For example, the Italian National Institute for Occupational Safety and Prevention was included in the National Insurance Company. Similar "reorganizations" occurred in France and very recently in Switzerland.

This aggressive attitude towards $\mathrm{OH}$ from the politicians and decision-makers is well illustrated by the Prime Minister's declaration, in the UK, in 2012: "We are waging war against the excessive health and safety culture that has become an albatross around the neck of the British businesses" [12]. A lot of people share this view that is a biased feeling of the reality (already mentioned in the introduction). There are no evidenced-based studies proving that "Health and safety culture" impacts negatively on the economy but there is a lot of scientific and economic evidence that proves exactly the opposite [13]. We may discuss the fact that this quotation mentioned "excessive" H\&S culture that impacts negatively on business. This may be true in some way, but it has not yet been demonstrated by any serious investigations.

\subsection{Strong Impact of Lobbies against the Prevention of Occupational Diseases}

The influence of the lobbies that put their priorities in the profits they get from 
their products and not on the negative health impacts they have on the public or on the workers, is considerable. The tobacco industry has demonstrated how efficient it can be in hiring competent scientists to focus on the limitations of epidemiologic studies in order to cast doubts on their results. The same is true for the chemical and pharmaceutical industry as well as for networks defending asbestos, silica and many other poisons [14] [15]. The drastic consequences of their political and economic pressure on decision-makers are tremendous in terms of suffering, diseases and death of thousands of people including a lot of workers every year.

\subsection{Obvious Lack of Awareness about Economic and Social Stakes}

The direct and indirect costs of Occupational Safety and Health Problems represent a huge economic burden on society. Experts have shown that these costs that are largely underestimated due to the poor visibility of the occupational diseases, are nevertheless bigger than those attributed to cancer, diabetes, coronary heart diseases, etc. [16] as illustrated in Figure 2.

Moreover, the costs of absenteeism, presenteeism, psychosocial problems, loss of performance and quality of work have been shown to be extremely high and confirm that the working conditions are quite an important factor that generates an economic burden on the companies and the society. It is not in the scope of this paper to enter into details of the numerous studies related to these costs but a report of the European Agency for Occupational Safety and Health is a good illustration of this problem [17].

Here again, these figures do not have apparently any influence on governments' policies. The reasons to explain this attitude are difficult to find. Is it a lack of awareness, a denial of reality or a cynical position?

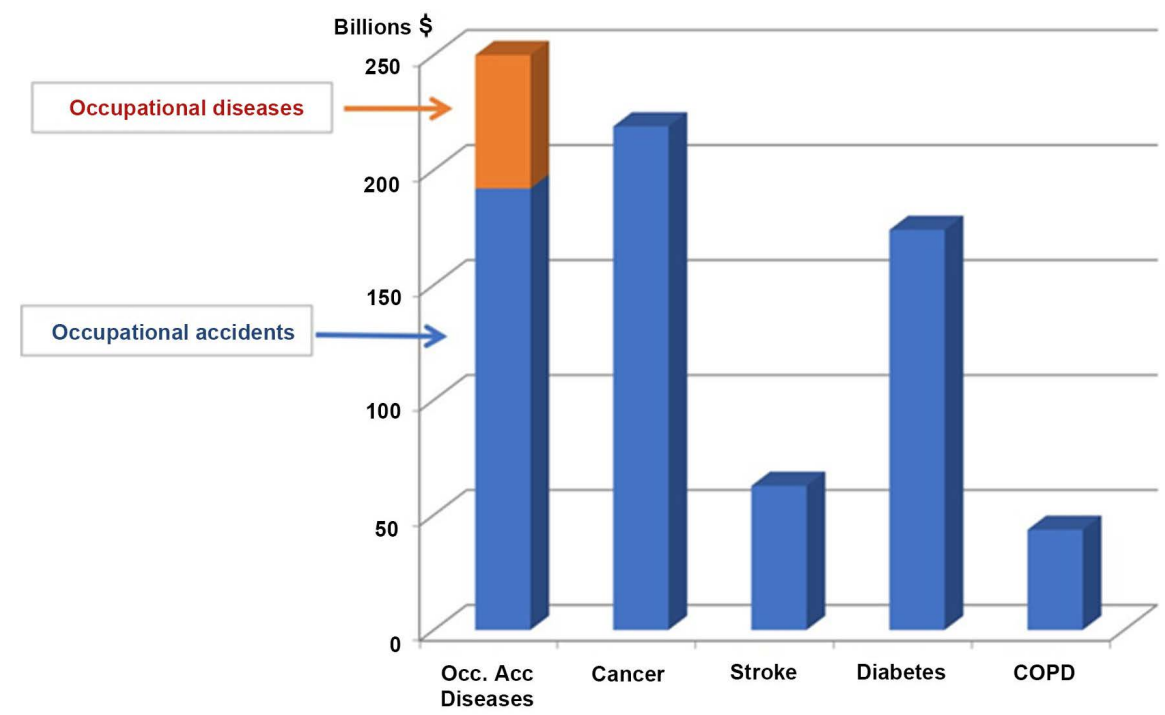

Figure 2. Graph showing the economic burden of occupational accidents and diseases in the USA, in comparison with a few major health problems such as Cancer, Diabetes, Stroke and Chronic Obstructive Pulmonary Disease (COPD). 


\section{A Global Approach Needs a Global Concept of Health}

\subsection{Examples of Existing Global Approaches}

In 2011, the National Institute for Occupational Safety and Health (NIOSH) in

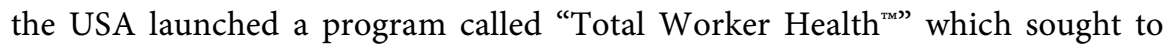
advance holistic well-being of workers through policies, programs and practices that integrated protection from work-related safety and health hazards with promotion of injury and illness prevention efforts. [18] According to the NIOSH Director, John Howard: “The NIOSH TWH ${ }^{T M}$ strategy champions interventions that comprehensively address work and non-work threats in a harmonized way". It is the first time that the "non-work" part of the workers' life is included in such a program. Although this may seem logical, it is revolutionary in term of social policy that has always established a close separation between the professional and the private life [19]. Such a global approach corresponds to our changing world of work where the borders between the work and non-work activities are becoming less and less strict.

Another comprehensive approach has been adopted by the WHO with its program "Healthy Workplaces", in which workers and managers collaborate to use a continual improvement process to protect and promote the health, safety and well-being of all workers and the sustainability of the workplace [20]. In this model, the four main components are: the physical work environment, the psychosocial work environment, the personal health resources and the enterprise community involvement (social responsibility). These third and fourth elements concern also the private life of the individual.

More recently the International Social Security Association (AISS) has launched a campaign called "Vision Zero" based on the belief that accidents, diseases and harm at the workplace are preventable and on the commitment of the companies and their partners. The core values of this campaign are Safety, Health and Wellbeing, and a methodology has been developed and tested to promote these values [21]. Although this strategy is focused mainly on the workplace, it is interesting by the fact it uses the concept of "vision" that is not usual in $\mathrm{OH}$ and more familiar to managers for the development and success of their companies. A vision is the description of a perfect and ideal state that will presumably never be reached but that gives the direction to take. In this way, it is also a global approach.

\subsection{Global Concept of $\mathrm{OH}$ : The Need of a Vision}

To be fully relevant a program that promotes $\mathrm{OH}$ globally must be based on a clear definition of $\mathrm{OH}$. Unfortunately, this comprehensive definition is missing and has been replaced, up to now, by the description of the objectives of this domain. The International Commission on Occupational Health (ICOH) that is the undisputed reference on this matter, has adopted the definition of the Joint Committee on Occupational Health of the World Health Organization (WHO) and of the International Labor Organization (ILO) [22]. This definition de- 
scribes the aims $\mathrm{OH}$ practice should meet but not the vision of $\mathrm{OH}$ itself.

One way to get the vision of $\mathrm{OH}$ is to refer to the WHO definition "Health" which is, in fact, a vision: a state of complete physical, mental and social well-being and not merely the absence of disease or infirmity. The fact that it is called a "definition" has been challenged and criticized since such a "state of complete wellbeing" is never reached [23]. These criticisms can be easily understood but neglect the fact that this statement has been issued in 1946 (more than 70 years ago) when the concept of a vision did not exist. Now, it should be renamed by the World Health Assembly (WHA), but such a procedure would be very long and complicated due to the multiple cultural, political and personal feelings of the WHA members.

\subsection{Global Health at Work Implies a Moral Dimension}

35 years ago (in 1984), the Director General of WHO published a report for the Executive Board explaining why the spiritual dimension of Health was important and why it should be included in the program called "Global Strategy for Health for All by the Year 2000". Following this recommendation, the WHA took the historic decision to include the spiritual wellbeing in this program [24]. For the same reasons that are mentioned above, no attempt was set about a modification of the old "definition of Health" at the WHA ${ }^{1}$.

Therefore, the vision of $\mathrm{OH}$ can be defined as a complete state of physical, mental, social and spiritual wellbeing at work. Figure 3 illustrates this vision and the mutual interactions that arise between the four elements.

For the mission and objectives of $\mathrm{OH}$, the aims defined by the ILO/WHO Joint Committee in 1995, sound still quite relevant.

It should be stressed that the word "spiritual" is still marked with fears of religious, sectarian or esoteric influences and is often replaced by the word "moral". Moreover, most of the $\mathrm{OH}$ professionals are following the Code of Ethics published by the ICOIH [25] that is intimately related to moral issues.

\section{The Emerging Issues That Need more Emphasis}

Up to now the major efforts of $\mathrm{OH}$ concern the risks of adverse effects on workers' health. This makes sense since the priority is to protect health. Substantial progress has been made for the "traditional hazards" (chemical and physical hazards, ergonomics) due to the fact that the professionalism of the experts in risk management has been improved over the years. However, $\mathrm{OH}$ opening to emerging issues towards health promotion-included in the ILO/WHO definition of $\mathrm{OH}$-has been rather slight. It is interesting to notice that ICOH has 37 scientific committees and no one is devoted to health promotion as such or to any of the specific topics presented in this chapter [26].

${ }^{1} \mathrm{~A}$ reliable source at the $\mathrm{WHO}$ - who does not want to be named-told the author of this paper that, the inclusion of the spiritual dimension of Health was planned in 1946 but that countries from Eastern Europe categorically refused. 


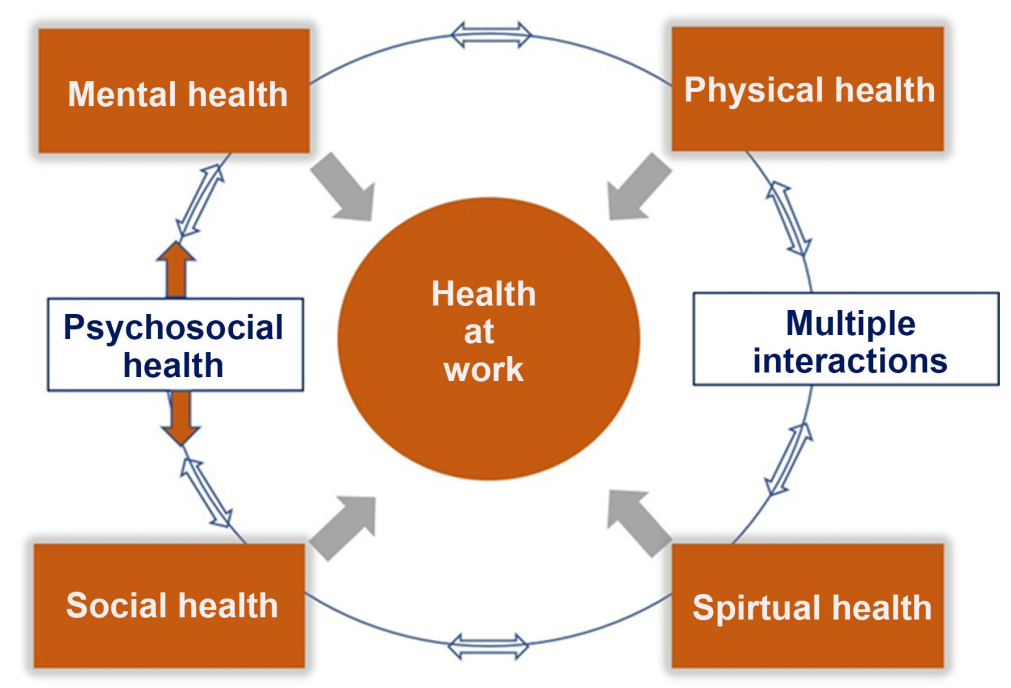

Figure 3. Simplified model of the vision of Health at Work from a global perspective. The four dimensions (Mental, Physical, Social and Spiritual Health) are inter-related which means that an impact on one of these dimensions may influence the other ones.

Wellbeing at work cannot be considered as an emerging issue. It is included in the global programs mentioned above such as the Total Worker Health" or the WHO "Healthy Workplace" and is also extensively treated in congresses and conferences by occupational psychologists and sociologists but remains rather far from sciences like salutogenesis, positive psychology or neurosciences that could go deeper in its scientific aspects.

\subsection{Salutogenesis}

This science has been developed in the seventies by a sociologist and academician, Aaron Antonovsky, who revolutionized the health approach by focusing on factors that promote "good health" and wellbeing rather than on factors that induce diseases (the field of medicine). The theory of this science is based on the concept called "Sense of Coherence" that determines whether stress will cause you harm, or will stimulate your dynamic feeling of confidence that the stimuli occur in your life in a structured, predictable and understandable way, and that you have the resources to cope with because they are meaningful for your personal development. Antonovsky died early in 1994 and his work has been pursued by Bengt Lindström and colleagues in Norway and other Scandinavian countries [27]. Application of Salutogenesis to work is rather recent but quite promising [28]. At the University of Zürich (Switzerland) a Center of Salutogenesis was created at the Biostatistics, Epidemiology and Prevention Institute in order to support this Science and boost research at the workplace [29]. We should hope other universities and research centers for $\mathrm{OH}$ will do the same.

\subsection{Positive Psychology}

This science emerged in the late nineties when psychologists like Martin Selig- 
man, supported by other colleagues, decided to turn psychology towards factors that promote happiness and wellbeing rather than on factors that induce illnesses or depression [30]. There is a strong analogy in this approach with salutogenesis that focuses on the other direction than medicine. Both approaches are useful and complementary.

Positive psychology entered the $\mathrm{OH}$ domain in recent years, but the field lacks a comprehensive and practice-based overview of this trend [31].

One interesting research area concerns the humanistic psychology in the workplace and the new organizational and management strategies that bring surprisingly good results for the workers' satisfaction and economic performance. A well-known psychologist in this field, Jacques Lecomte, made a large survey on these "humanistic enterprises" where he showed that human values guiding the management (respect, altruism, benevolence, justice, etc.) and determination in assuming their social responsibilities, are key factors for the success of these enterprises [32]. A similar approach was carried out by an economist (Frederic Laloux) looking for "soulful organizations" focusing on these values and triggering profound changes in consciousness, culture, organization and social systems. One of the major values that he discovered was confidence. Companies that trust their employees, employees that trust their management, clients that trust their suppliers, etc. are building a new world "inspired by the next stage of Human consciousness", according to the words of the author [33].

\subsection{Neurosciences}

This multidisciplinary scientific study of the nervous system has made amazing progress by discovering the neuroplasticity that allows remodeling of the neurosynaptic organization aiming at optimizing the functioning of the neural networks [34]. It has been shown, for instance, that the brain areas that are activated during meditation may act on control of pain, decrease of anxiety, speeding up of recoveries, improvement of mental performances, etc. [35]. Moreover, these findings highlight the view that well-being is best regarded as a skill that can be enhanced through training [36] [37]. This open new prospects for wellbeing at work [38] that need to be further developed, keeping in mind that from an ethical point of view, the priority at the workplace is to avoid as much as possible stressful working conditions (through organizational measures) before helping workers to cope with these conditions (individual measures). The famous Mindfulness-Based Stress Reduction (MBSR) method developed by J. Kabat-Zinn in the eighties has been shown to be quite efficient at the individual level but does not solve the problem of bad working conditions [39].

\subsection{Managers' Health}

In the legal framework of Occupational Safety and Health (OSH), managers are not considered as "workers" although they work hard and may also suffer from different pains (stress, burnout, coronary heart disease, diabetes, etc.). Moreover, 
if they are owners of their company or enterprise, they are not protected by the social system. This area of research has been neglected up to now or extremely limited [40] and should be promoted as a quite relevant topic: Managers' health impacts on employees' health and on the company itself. In small and medium-sized enterprises (SMEs), the manager feels often alone and cannot share his problems and doubts with his (her) employees that could lose confidence and feel unsafe for their job.

In France-and maybe in other countries-an Observatory (called Amarok) was created in 2008 and is still looking for the physical and mental health of independent workers, members of liberal professions, SMEs' owners, craftsmen, etc. in order to raise the awareness of the public opinion about the importance of this problem and to build a bridge between medical and entrepreneurial sciences [41].

\subsection{Collaboration with "Decision-Makers"}

A real dialogue between the $\mathrm{OH}$ professionals and the decision-makers is missing because there is a lack of mutual confidence and the discussion remains focused on legal issues and not on the deep roots of good working conditions. For instance, at the international level, the tripartite approach of the ILO where the employers, employees and government are represented, is focused on legal, administrative and social security aspects (finalized in "Conventions" or "Recommendations") in order to set out basic principles and rights at work.

The world of enterprises and the world of $\mathrm{OH}$ remain enclosed in their own silo and there are no effective connections between the silos. The lack of confidence, issued from the prejudice mentioned above, is one important brake on building a dialogue. Historical perspectives, such as the political opposition between the right side that defends employers and the left side that defends employees are still playing a role in this respect although it is becoming a less and less relevant caricature except for those sticking at the old paradigms. Another factor is the lack of mutual understanding of the problems specific to each world. They remain each one focused on their own specific issues without realizing that they are inter-related with those of the other silo, such as the managers' health presented above.

Platforms, networks, meetings, specific events and any other possibilities should be used to build up a true dialogue that goes beyond the traditional discussions and opens new avenues where the global concept of $\mathrm{OH}$ is used and the promising emerging issues listed in this paper are promoted. Such an attempt has been done in the French-speaking part of Switzerland and is still running [42].

\section{Whose Responsibility Is It?}

The poor $\mathrm{OH}$ visibility as well as its decline is, in some way, compensated in the field by Health Promotion at the workplace but not at the level of psychosocial 
and moral risks. This means that healthy workplaces in healthy enterprises need to be promoted by all the actors. And this cannot be achieved without a scientific and economic approach, first to understand the causes of its deterioration and second to adapt education and training of the concerned professionals. All the partners that can contribute to reverse this worsening trend and to develop a healthy society, have, therefore, the responsibility to take action.

\subsection{Academic Institutions and Centers for Research and Education}

Research and education are the two main linchpins for improving the present situation. Without scientific and economic evidence nothing can be seriously undertaken. For the issues that concern healthy workplaces and healthy enterprises, there is a considerable lack of knowledge. This is, therefore, the responsibility of these institutions to release credits and to support research and education in these areas. In this respect, the role of international organizations and associations should not be underestimated. The situation is worrying for $\mathrm{OH}$ that lost in many countries a lot a research centers in the last decades, and the curricula for education and training do not seem to be adequately adapted to the actual changes. This appears not to be the case for business and management since some business schools have started to make research on the new types of corporate governance and to provide courses related to wellbeing at work through a benevolent leadership [43].

\subsection{Occupational Health Professionals}

All the $\mathrm{OH}$ professionals and experts have to enlarge the scope of their specific field and to adapt to the changing world of work in order to be more efficient in helping the social partners to better cope with the challenges of the present situation. They should also improve their knowledge in business administration to better understand employers' problems and to be able to establish a real dialogue with them.

\subsection{SME Owners and CEOs of Large Organizations}

The lack of awareness as well as the poor knowledge of these actors about $\mathrm{OH}$ needs to be filled in some way by training and education, in order to build up the appropriate conditions to collaborate with the $\mathrm{OH}$ professionals. This will also result in a better perception of how to take care of their own health.

In the present situation and in most cases, they delegate their responsibilities regarding Occupational Health and Safety (OHS) to professionals in this field, without getting personally involved. Therefore, these issues are not a priority.

\subsection{Social Partners}

Employers, employees and government representatives should also open the scope of their discussions beyond the legal, administrative and social security aspects of $\mathrm{OH}$. A change of attitude is also needed since the "traditional opposi- 
tion between employees and employers" remains apparently a reality, at least in the international organizations. The fact that work is changing rapidly and is becoming more digital (artificial intelligence and robots), more flexible with different business models (uberization), less stable, etc. will make the usual approach obsolete and will be an opportunity to set up new bases for shaping the future of work in a more harmonized and beneficial way for all the partners.

\subsection{Decision-Makers (Politicians)}

This represents probably the biggest challenge since the economic stakes are predominant and have priority and do not yet integrate the positive impact of "healthy workers". The politicians' addresses do not reflect any awareness in this line for the moment. Quite indecent attitudes still exist about asbestos for instance in countries where it is not yet banned for economic reasons. Therefore, this hazard cannot be properly controlled and cause cancers and pulmonary diseases in thousands of workers. Awakening of decision-makers' morale consciousness is urgently needed. Since politicians are elected by the people, we all bear a responsibility!

\section{Conclusions}

All those concerned by Public Health should understand that $\mathrm{OH}$ is an important matter and should participate to increase its visibility and its development. The situation looks different according to countries but we are not aware of any survey on this issue, illustrating that in countries where $\mathrm{OH}$ is better included in the PH policy, the situation is better than in the other countries. Moreover, the present indicators related to OHS are very poor. Even statistics on accidents have been shown to be not quite reliable [44] and it is well-known that statistics on diseases are useless since they rely only on insurance criteria and hide the majority of work-related diseases. The estimation of the "work-related diseases" not included in the official statistics is difficult to assess and efforts of the epidemiologists to evaluate the "attributable part" of work to diseases like cancer [45], heart stroke, diabetes, etc. have shown impressive figures that cannot allow getting a global picture of the real situation.

International surveys like those of Eurofound provide interesting data that allow some bench marking and the following of the evolution of some indicators related to wellbeing at work or to psychosocial problems for instance that continue to increase over the years.

The worrying facts reporting in the first chapter, as well as the recent studies showing that the global burden of injuries and diseases at work is huge [46] and do not have any impact on the decision-makers, demonstrating that they are not considering this problem as important. The reasons for the lack of awareness have been discussed in this paper and lie mainly in the fact that $\mathrm{OH}$ is not visible enough.

In fact, we are all concerned since we can act in our own environment either 
to participate in practice to promote $\mathrm{OH}$ or to disseminate information about the situation and the need to make a drastic change of our behavior and on the necessity to approach $\mathrm{OH}$ and its positive and constructive aspects from a global perspective without forgetting its moral dimension. Work may contribute to wellbeing and happiness and the ways that lead to this development are already known and still under study. It is our responsibility to promote this knowledge. Without such a collective effort the situation of $\mathrm{OH}$ will not improve.

This paper has summarized a few key elements to illustrate the unsuspected dimensions of $\mathrm{OH}$ [47] and its invaluable potentiality for contributing to a better society where work has to recover its fundamental function of the driver of human and social blooming.

\section{Conflicts of Interest}

The author declares no conflict of interests regarding the publication of this paper.

\section{Acknowledgements}

I would like to thank my wife, Monique Guillemin-Soler, for her careful review of this paper and for her meticulous checking of the references.

\section{Conflicts of Interest}

The authors declare no conflicts of interest regarding the publication of this paper.

\section{References}

[1] Eurofound (2016) Sixième enquête européenne sur les conditions de travail-Rapport général. Synthèse.

https://www.eurofound.europa.eu/sites/default/files/ef_publication/field_ef_docum ent/ef1634fr1.pdf

[2] Khireddine, I., Lemaître, A., Homère, J., Plaine, J., Garras, L., Riol, M.C. and Valenty, M. (2012) La souffrance psychique en lien avec le travail chez les salariés actifs en France entre 2007 et 2012, à partir du programme MCP. Bulletin Épidémiologique Hebdomadaire, 23, 431-438.

http://invs.santepubliquefrance.fr/beh/2015/23/pdf/2015_23_2.pdf

[3] Travail Suisse (2018) Lacunes dans la prévention des risques psychosociaux. https://www.presseportal.ch/fr/pm/100020454/100817130

[4] Steel, J., Luyten, J. and Godderis, L. (2018) Occupational Health: The Global Evidence and Value.

https://www.som.org.uk/sites/som.org.uk/files/Occupational_Health_the_Global_V alue_and_Evidence_April_2018.pdf

[5] Ryder, G. (2018) Persistent and Growing Inequality Threatens Global Growth. Statement. 2018 Annual Meetings of the World Bank and the IMF, Washington, 18 April 2018.

https://www.ilo.org/global/about-the-ilo/newsroom/statements-and-speeches/WC MS_626195/lang--en/index.htm

[6] World Health Organization (WHO) (2016) Life Expectancy Increased by 5 Years since 2000, but Health Inequalities Persist. News Release, Geneva, Switzerland. 
https://www.who.int/news-room/detail/19-05-2016-life-expectancy-increased-by-5years-since-2000-but-health-inequalities-persist

[7] Schuring, M., Schram, J.L.D., Robroek, S.L.W. and Burdorf, A. (2019) The Contribution of Health to Educational Inequalities in Exit from Paid Employment in Five European Regions. Scandinavian Journal of Work and Environmental Health, Online-First-Article. https://doi.org/10.5271/sjweh.3796

[8] Occupational Safety and Health Administration (OSHA) (2015) Adding Inequality to Injury: The Costs of Failing to Protect Workers on the Job. OSHA, Washington. http://labor.vermont.gov/wordpress/wp-content/uploads/Inequality2015.pdf

[9] Ahonen, E.Q., Fujishiro, K., Cunningham, T. and Flynn, M. (2018) Work as an Inclusive Part of Population Health Inequities Research and Prevention. American Journal of Public Health, 108, 306-311. https://doi.org/10.2105/AJPH.2017.304214

[10] Westerholm, P. (2007) Closing the Swedish National Institute for Working Life. Occupational and Environmental Medicine, 64, 787-788. https://doi.org/10.1136/oem.2007.034207

[11] Wegman, D.H., Burdorf, A., Oldershaw, P., Schulte-Fortkamp, B. and Viikari-Juntura, E. (2007) International Evaluation of Swedish Work Environment Research. Scandinavian Journal of Work and Environmental Health, 33, 32-45.

[12] Woodcock, A., Bentley, D. and Glaze, B. (2012) David Cameron: I Will Kill off Safety Culture: David Cameron Today Said that His New Year's Resolution Was to "Kill off the Health and Safety Culture for Good". Independent. http://www.independent.co.uk/news/uk/politics/david-cameron-i-will-kill-off-safet y-culture-6285238.html

[13] Mossink, J.C.M. and Nelson, D.I. (2004) Understanding and Performing Economic Assessments at the Company Level. World Health Organization, Protecting Workers' Health Series No.2.

https://www.who.int/occupational_health/publications/en/pwh2e.pdf

[14] Sass, J. and Rosenberg, D. (2011) The Delay Game: How the Chemical Industry Ducks Regulation of the Most Toxic Substances. NRDC (Natural Resources Defense Council), New York. https://www.nrdc.org/sites/default/files/IrisDelayReport.pdf

[15] Michaels, D. (2008) Doubt Is Their Product: How Industry's Assault on Science Threatens Your Health. Oxford University Press, New York.

[16] Leigh, J.P. (2011) Economic Burden of Occupational Injury and Illness in the United States. The Milbank Quarterly, 89, 728-772. https://doi.org/10.1111/j.1468-0009.2011.00648.x

[17] Hassard, J., Teoh, K., Cox, T., Dewe, P., Cosmar, M., Gründler, R., Flemming, D., Cosemans, B. and Van den Broek, K. (2014) Calculating the Cost of Work-Related Stress and Psychosocial Risks. European Risk Observatory-Literature Review. European Agency for Safety and Health at Work (EU-OSHA).

https://osha.europa.eu/en/tools-and-publications/publications/literature_reviews/ca lculating-the-cost-of-work-related-stress-and-psychosocial-risks

[18] The National Institute for Occupational Safety and Health (NIOSH) (2011) Total Worker Health: What Is Total Worker Health? CDC, NIOSH. https://www.cdc.gov/niosh/twh/totalhealth.html

[19] Paraventi, M. (2015) Total Worker Health ${ }^{\text {Tm }}$ Integrates On- and Off-the-Job Safety \& Health. Industrial Safety and Hygiene News (ISHN).

https://www.ishn.com/articles/102418-total-worker-health-integrates-on--and-off-t he-job-safety-health

[20] World Health Organization (WHO) (2011) Five Keys to Health Workplaces. https://www.who.int/occupational_health/5_keys_EN_web.pdf?ua=1 
[21] International Social Security Association (ISSA) (2017) Vision Zero: 7 Golden Rules-For Zero Accidents and Healthy Work. A Guide for Employers and Managers. ISSA.

http://visionzero.global/sites/default/files/2017-12/2-Vision\%20Zero\%20Guide-We b.pdf

[22] Rantanen, J. and Fedotov, I.A. (2011) Standards, Principles and Approaches in Occupational Health Services. In: Stellman, J.M., Ed., Encyclopaedia of Occupational Health and Safety, 4th Edition, Part II, Chapter 16. Occupational Health Services. http://www.iloencyclopaedia.org/part-ii-44366/occupational-health-services https://doi.org/10.1093/acprof:oso/9780195380002.003.0001

[23] Huber, M., Knottnerus, J.A., Green, L., Van der Horst, H., Jadad, A.R., Kromhout, D., Leonard, B., Lorig, K., Loureiro, M.A., van der Meer, J.W.M., Schnabel, P., Smith, R., van Weel, C. and Smid, H. (2011) How Should We Define Health? British Medical Journal, 343, d4163. https://www.bmj.com/content/343/bmj.d4163.full https://doi.org/10.1136/bmj.d4163

[24] World Health Organization, World Health Assembly (1984) The Spiritual Dimension in the Global Strategy for Health for All by the Year 2000. Resolution of the World Health Assembly, Thirty-Seventh World Health Assembly Agenda Item 19. https://apps.who.int/iris/bitstream/handle/10665/160950/WHA37_R13_eng.pdf?seq uence $=1$

[25] International Commission on Occupational Health (ICOH) (2014) International Code of Ethics of Occupational Health Professionals, 3rd Edition.

http://www.icohweb.org/site/multimedia/code_of_ethics/code-of-ethics-en.pdf

[26] International Commission on Occupational Health (ICOH) (2019) Scientific Committees. http://www.icohweb.org/site/scientific-committees.asp

[27] Lindström, B. (2010) Salutogenesis. An Introduction. http://www.centrelearoback.org/assets/PDF/04_activites/clr-GCPB121122-Lindsto m_pub_introsalutogenesis.pdf

[28] Jenny, G.J., Bauer, G.F., Forbech Vinje, H., Vogt, K. and Torp, S. (2017) The Application of Salutogenesis to Work. In: Mittelmark, M.B., Sagy, S., Eriksson, M., Bauer, G.F., Pelikan, G.M., Lindström, B. and Espnes, G.A., Eds., The Handbook of Salutogenesis. Springer, Cham, Switzerland, 197-210.

https://www.researchgate.net/publication/311995664_The_Application_of_Salutoge nesis_to_Work

[29] University of Zürich (2017) Center for Salutogenesis. UZH, Symposium on Salutogenesis, Zurich, 8 September 2017.

https://www.ebpi.uzh.ch/en/aboutus/departments/publichealth/poh/salutogenesis.h $\underline{\mathrm{tml}}$

[30] Ackerman, C. and Fonate-Pennock, S. (2019) What Is Positive Psychology \& Why Is It Important? Positive Psychology Program.

https://positivepsychologyprogram.com/what-is-positive-psychology-definition/

[31] Mills, M.J., Fleck, C.R. and Kozikowski, A. (2013) Positive Psychology at Work: A Conceptual Review, State-Of-Practice Assessment, and a Look ahead. The Journal of Positive Psychology, 8, 153-164. https://doi.org/10.1080/17439760.2013.776622

[32] Lecomte, J. (2016) Les entreprises humanistes: Comment elles vont changer le monde (Humanistic Enterprises: How they will change the world). Les Arènes, Paris.

[33] Laloux, F. (2014) Reinventing Organizations. A Guide to Creating Organizations Inspired by the Next Stage of Human Consciousness. Nelson Parker, Brussels, Belgium.

[34] Neuroplasticity (2019) Learn More about Neuroplasticity. 
https://www.sciencedirect.com/topics/neuroscience/neuroplasticity

[35] Carlson, L.E. and Garland, S.N. (2005) Impact of Mindfulness-Based Stress Reduction (MBSR) on Sleep, Mood, Stress and Fatigue Symptoms in Cancer Outpatients. International Journal of Behavioral Medicine, 12, 278-285. https://doi.org/10.1207/s15327558ijbm1204_9

[36] Lutz, A., Slagter, H.A., Rawlings, N.B., Francis, A.D., Greischar, L.L. and Davidson, R.J. (2009) Mental Training Enhances Attentional Stability: Neural and Behavioral Evidence. Journal of Neuroscience, 29, 13418-13427. https://doi.org/10.1523/JNEUROSCI.1614-09.2009

[37] Davidson, R.J. and Schuyler, B.S. (2015) Neuroscience of Happiness. In: Helliwell, J.F., Laryard, R. and Sachs, J., Eds., World Happiness Report 2015, Sustainable Development Solutions Network, New York, 82-105. http://unsdsn.org/wp-content/uploads/2015/04/WHR15.pdf

[38] Bostock, S., Crosswell, A.D., Prather, A.A. and Steptoe, A. (2018) Mindfulness On-the-Go: Effects of a Mindfulness Meditation App on Work Stress and Well-Being. Journal of Occupational Health Psychology, 24, 127-138. https://doi.org/10.1037/ocp0000118

[39] Kabat-Zinn, J. (2005) Full Catastrophe Living: Using the Wisdom of Your Body and Mind to Face Stress, Pain, and Illness (15th Anniversary Edition). Delta Trade Paperback/Bantam Dell, New York.

[40] Fernet, C., Torrès, O., Austin, S. and St-Pierre, J. (2016) The psychological costs of owning and managing an SME: Linking job stressors, occupational loneliness, entrepreneurial orientation and burnout. Burnout Research, 3, 45-53.

https://doi.org/10.1016/j.burn.2016.03.002

[41] Observatoire Amarok (2019) Présentation: L’Observatoire Amarok met son expertise au service des chefs d'entreprise.

http://www.observatoire-amarok.net/sites/wordpress/index.php/our-process-2/

[42] Association Santé Globale et Travail (Association Global Health and Work) (2019) https://www.sante-globale-travail.org/

[43] Grenoble École de Management (2019) Dominique Steiler, Head of Centre for Personal and Managerial Development. https://en.grenoble-em.com/annuaire/dominique-steiler

[44] Kharel, U. (2016) The Global Epidemics of Occupational Injuries: Counts, Costs, and Compensation. Dissertation presented at Pardee RAND Graduate School. RAND Corporation, Santa Monica, USA.

https://www.rand.org/content/dam/rand/pubs/rgs_dissertations/RGSD300/RGSD3 77/RAND_RGSD377.pdf

[45] Purdue, M.P., Hutchings, S.J., Rushton, L. and Silverman, D.T. (2015) The Proportion of Cancer Attributable to Occupational Exposure. Annals of Epidemiology, 25, 188-192. https://www.ncbi.nlm.nih.gov/pmc/articles/PMC4631263/ https://doi.org/10.1016/j.annepidem.2014.11.009

[46] Takala, J., Hämäläinen, P., Saarela, K.L., Yun, L.Y., Manickam, K., Jin, T.W., Heng, P., Tjong, C., Kheng, L.G., Lim, S. and Lin, G.S. (2014) Global Estimates of the Burden of Injury and Illness at Work in 2012. Journal of Occupational and Environmental Hygiene, 11, 326-337.

https://www.ncbi.nlm.nih.gov/pmc/articles/PMC4003859/ https://doi.org/10.1080/15459624.2013.863131

[47] Guillemin, M. (2011) Les dimensions insoupçonnées de la Santé au Travail (The Unsuspected Dimensions of Health at Work). L'Harmattan, Paris. 